\title{
The Effect of China's One-Child Family Policy after 25 Years
}

\author{
Therese Hesketh, Ph.D., Li Lu, M.D., and Zhu Wei Xing, M.P.H.
}

China's one-child family policy has had a great effect on the lives of nearly a quarter of the world's population for a quarter of a century. When the policy was introduced in 1979, the Chinese government claimed that it was a short-term measure and that the goal was to move toward a voluntary small-family culture. ${ }^{1}$ In this article, we examine to what extent this goal has been achieved and the implications for the future of the policy. First we explain why the policy was introduced and how it is now implemented. We also examine the consequences of the policy in regard to population growth, the ratio between men and women, and the ratio between adult children and dependent elderly parents. Finally, we examine the relevance of the policy in contemporary China and whether the time has come for the policy to be relaxed.

\section{BACKGROUND}

In 1979, the Chinese government embarked on an ambitious program of market reform following the economic stagnation of the Cultural Revolution. At the time, China was home to a quarter of the world's people, who were occupying just 7 percent of world's arable land. Two thirds of the population were under the age of 30 years, and the baby boomers of the 1950s and 1960s were entering their reproductive years. The government saw strict population containment as essential to economic reform and to an improvement in living standards. ${ }^{2}$ So the one-child family policy was introduced.

The policy consists of a set of regulations governing the approved size of Chinese families. These regulations include restrictions on family size, late marriage and childbearing, and the spacing of children (in cases in which second children are permitted). The State Family Planning Bureau sets the overall targets and policy direction. Family-planning committees at provincial and county levels devise local strategies for implementation. Despite its name, the one-child rule applies to a minority of the population; for urban residents and government employees, the policy is strictly enforced, with few exceptions. The exceptions include families in which the first child has a disability or both parents work in high-risk occupations (such as min- ing) or are themselves from one-child families (in some areas).

In rural areas, where approximately 70 percent of the people live, a second child is generally allowed after five years, but this provision sometimes applies only if the first child is a girl - a clear acknowledgment of the traditional preference for boys. ${ }^{3}$ A third child is allowed among some ethnic minorities and in remote, underpopulated areas. The policy is underpinned by a system of rewards and penalties, which are largely meted out at the discretion of local officials and hence vary widely. They include economic incentives for compliance and substantial fines, confiscation of belongings, and dismissal from work for noncompliance.

The policy depends on virtually universal access to contraception and abortion. A total of 87 percent of all married women use contraception ${ }^{4}$; this statistic compares with about one third in most developing countries. ${ }^{5}$ There is heavy reliance on longterm contraception, with intrauterine devices and sterilizations together accounting for more than 90 percent of contraceptive methods used since the mid-1980s. ${ }^{4,6}$ The number of sterilizations has declined since the peak in the early 1990s (Table 1). For the majority of women, no choice in contraception is offered; 80 percent of women in a recent large study said they had no choice and just accepted the method recommended by the family-planning worker. ${ }^{4}$ The use of these long-term methods

\begin{tabular}{|lrrrrr|}
\hline \hline $\begin{array}{l}\text { Table 1. Trends in the Use of Contraceptive Methods among Married } \\
\text { Chinese Women, 1982 to 2001.* }\end{array}$ & 1982 & 1988 & 1992 & 1997 & 2001 \\
\hline Contraceptive Method & 10 & 13 & 12 & 9 & 8 \\
Male sterilization & 25 & 37 & 42 & 40 & 37 \\
Female sterilization & 50 & 40 & 40 & 43 & 46 \\
Intrauterine device & 2 & 2 & 2 & 4 & 6 \\
Condom & 8 & 5 & 4 & 2 & 3 \\
Oral contraceptive pill & 5 & 3 & $<1$ & 1 & 1 \\
Other method & & & & & \\
\hline
\end{tabular}


keeps abortion rates relatively low, with 25 percent of women of reproductive age having had at least one abortion, as compared with 43 percent in the United States. ${ }^{7}$ The main reasons given for abortion are contraceptive failure and a lack of government approval for the pregnancy under the one-child policy. ${ }^{8}$ Women who proceed with an unapproved pregnancy are known to be reluctant to use antenatal and obstetric services because they fear they will face pressure to have an abortion or fines for violating the one-child policy.9,10 Many deliveries of babies that have not been officially sanctioned occur at home without trained personnel, a practice that is associated with the risk of maternal or neonatal mortality. A study carried out in rural Sichuan province in 1990 reported a doubling of maternal deaths for unapproved pregnancies as compared with those receiving government sanction. ${ }^{11}$

\section{POPULATION GROWTH}

When the one-child policy was introduced, the government set a target population of 1.2 billion by the year 2000. The census of 2000 put the population at 1.27 billion, ${ }^{12}$ although some demographers regard this number as an underestimate. ${ }^{13}$ The collection of population statistics in China is known to be subject to manipulation to conform with family-planning regulations, since the process is overseen by officials who are often unwilling to uncover any violations of the rules. ${ }^{14,15}$ Chinese authorities claim that the policy has prevented 250 to 300 million births. The total fertility rate, which is defined as the mean number of children born perwoman, decreased from 2.9 in 1979 to 1.7 in 2004, with

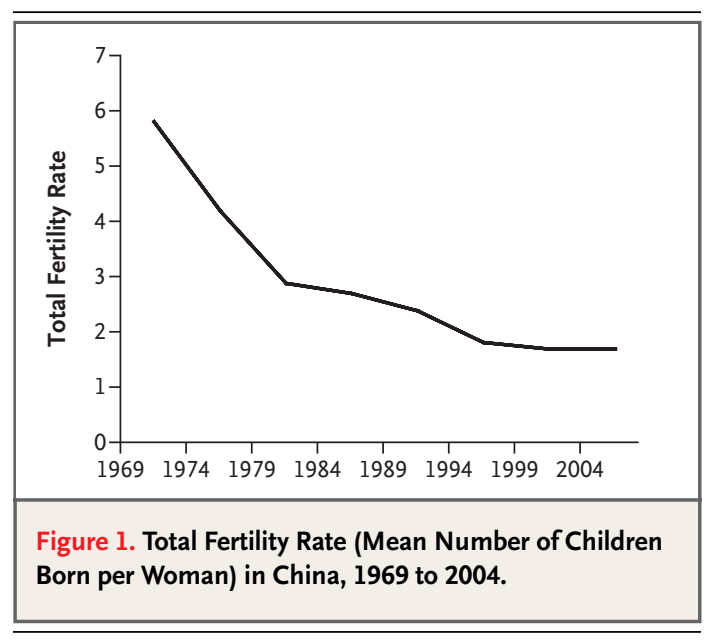

a rate of 1.3 in urban areas and just under 2.0 in rural areas. ${ }^{16}$ This trend has created a distinct demographic pattern of urban families with predominantly one child and rural families with predominantly two children.

However, the policy itself is probably only partially responsible for the reduction in the total fertility rate. The most dramatic decrease in the rate actually occurred before the policy was imposed (Fig. 1). Between 1970 and 1979, the largely voluntary "late, long, few" policy, which called for later childbearing, greater spacing between children, and fewer children, had already resulted in a halving of the total fertility rate, from 5.9 to $2.9 .^{3}$ After the one-child policy was introduced, there was a more gradual fall in the rate until 1995, and it has more or less stabilized at approximately 1.7 since then. ${ }^{16}$ In addition, many countries have had substantial declines in fertility during the past 25 years, and China's neighbors in East Asia have some of the lowest total fertility rates in the world: 1.04 in Singapore, 1.38 in Japan, and 0.91 in the Hong Kong Special Administrative Region. ${ }^{17}$ Even allowing for the fact that these countries are more developed and urbanized than China, the parallels are hard to ignore. It is reasonable to speculate that there would have been a further decline in China's total fertility rate had the voluntary policy of the 1970s continued.

THE SEX RATIO

The effect of the policy on the sex ratio has received much attention. The sex ratio at birth, defined as the proportion of male live births to female live births, ranges from 1.03 to 1.07 in industrialized countries. ${ }^{18}$ Since the onset of the one-child policy, there has been a steady increase in the reported sex ratio, from 1.06 in 1979 , to 1.11 in 1988 , to 1.17 in $2001 .{ }^{19}$ There are marked and well-documented local differences, with ratios of up to 1.3 in rural Anhui, Guangdong, and Qinghai provinces. Data from the 2001 National Family Planning and Reproductive Health Survey, which was carried out among a nationally representative sample of 39,600 women of reproductive age and is the most recent large-scale survey of reproductive health and fertility, show clearly that the increased sex ratio is not confined predominantly to rural China, ${ }^{19}$ as has been previously assumed ${ }^{20}$ (Table 2). There is a marked gradient across birth order: in rural areas, the sex ratio for the first birth is 1.05 (within nor- 
mal limits), but it rises steeply with birth order. In urban areas, the sex ratio is 1.13 for the first birth and peaks at 1.30 for the second birth but decreases for the third and fourth births (which are rare in urban areas). The picture that emerges is that some urban Chinese make the choice to perform sex selection with the first pregnancy, since they are allowed only one child. In rural areas, most couples are permitted to have a second child, especially if the first is female. So if the second (or subsequent) child is female, the pregnancy often "disappears," allowing the couple to have another child in an attempt to have a son.

What happens to all the missing girls is a matter of speculation. Sex-selective abortion after ultrasonography undoubtedly accounts for a large proportion of the decline in female births. ${ }^{20,21}$ Actual figures are impossible to obtain, because sex-selective abortion is illegal but is known to be widely carried out, helped by a burgeoning private sector. Nonregistration of female births also contributes to the sex-ratio gap. ${ }^{14,15}$ A 1995 household survey carried out in three provinces found a normal sex ratio in the under-14 age group, with the actual number of girls exceeding the number registered by 22 percent. ${ }^{22}$ Although infanticide of girls is probably very rare now, less aggressive treatment of sick female infants is known to occur. ${ }^{23}$

The Chinese government has acknowledged the potentially disastrous social consequences of this sex imbalance. The shortage of women may have increased mental health problems and socially disruptive behavior among men and has left some men unable to marry and have a family. ${ }^{24}$ The scarcity of females has resulted in kidnapping and trafficking of women for marriage and increased numbers of commercial sex workers, with a potential resultant rise in human immunodeficiency virus infection and other sexually transmitted diseases. ${ }^{25}$ There are fears that these consequences could be a real threat to China's stability in the future. ${ }^{26}$

Although the one-child policy has been blamed for the high sex ratio, it is probably just one contributory factor. There was a high sex ratio in China in the 1930s and 1940s, mostly resulting from infanticide of girls, and then the ratio declined in the years after the Communist Revolution of 1949.27 Many other Asian countries with declining fertility rates and a traditional preference for males are also seeing sex-ratio imbalances - Taiwan, 1.19; Singapore, 1.18; South Korea, 1.12; and parts of northern India, $1.20^{28}$ - largely because of sex-selective

\begin{tabular}{|lccc|}
\hline \hline \multicolumn{4}{|c|}{ Table 2. Ratio of Men to Women According to Birth Order in China, 1980 to 2001.* } \\
\hline Birth Order & In Urban Areas & In Rural Areas & Overall \\
First child & 1.13 & 1.05 & 1.06 \\
Second child & 1.30 & 1.23 & 1.24 \\
Third child & 1.19 & 1.29 & 1.28 \\
Fourth child or more & 1.19 & 1.32 & 1.31 \\
Average of all birth orders & 1.16 & 1.15 & 1.15 \\
\hline
\end{tabular}

* Data are from Kang and Wang. ${ }^{19}$

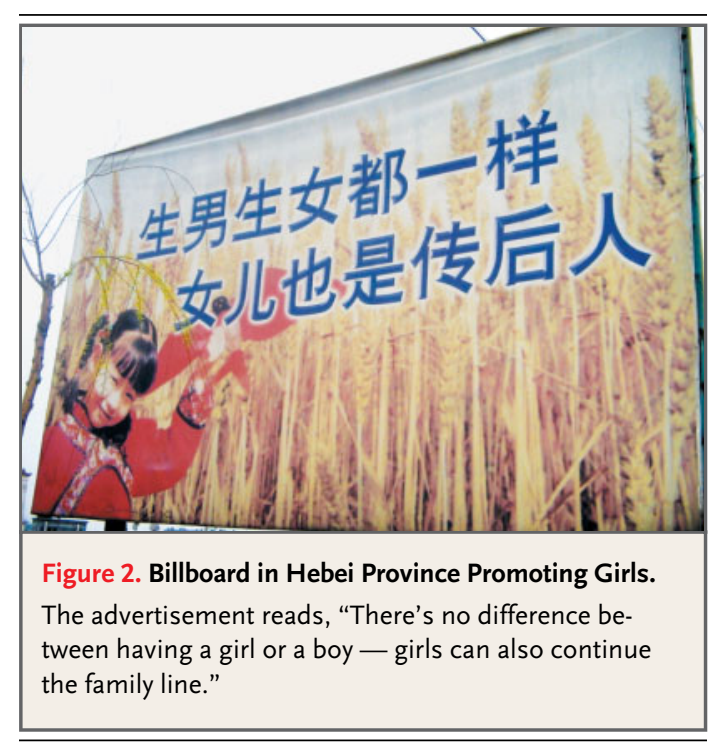

abortion. ${ }^{27}$ In China, the marked increase in the sex ratio between the 1980s and 1990s coincided with much easier access to cheap ultrasonography and not with any substantial change in enforcement of the one-child policy. It is likely, therefore, that even in the absence of the policy, sex-selective abortion would continue, although it would probably be less common. The solution will come only with a change in attitudes toward female offspring. Publicity campaigns promoting girls are now widespread and acknowledge the importance of such change (Fig. 2).

But there are some indications that the traditional preference for boys may be shifting. In the $\mathrm{Na}-$ tional Family Planning and Reproductive Health Survey, 37 percent of women (predominantly young, urban women) claimed to have no preference for one sex over the other, whereas 45 percent said the ideal family consisted of one boy and one girl. In fact, slightly more women expressed a preference for one girl (5.9 percent) than for one boy (5.6 percent). ${ }^{29}$ Although these expressed preferences have 
not yet been translated into a normalization of the sex ratio, this may happen in the near future.

RATIO OF OLD-AGE DEPENDENCY

The rapid decrease in the birth rate, combined with stable or improving life expectancy, has led to an increasing proportion of elderly people and an increase in the ratio between elderly parents and adult children. ${ }^{30}$ In China, the percentage of the population over the age of 65 years was 5 percent in 1982 and now stands at 7.5 percent but is expected to rise to more than 15 percent by $2025 .{ }^{28}$ Although these figures are lower than those in most industrialized countries (especially Japan, where the proportion of people over the age of 65 years is 20 percent), a lack of adequate pension coverage in China means that financial dependence on offspring is still necessary for approximately 70 percent of elderly people. ${ }^{31}$ Pension coverage is available only to those employed in the government sector and large companies. In China, this problem has been named the "4:2:1" phenomenon, meaning that increasing numbers of couples will be solely responsible for the care of one child and four parents.

Initiatives are under way to improve access to government pensions and to encourage saving for private pensions in an attempt to reduce the burden of the 4:2:1 phenomenon. ${ }^{7}$ In addition, a specific measure has been introduced to address the prob- lem: in urban areas, couples who are themselves both only children are allowed to have more than one child. As only children reach reproductive age, many couples will meet these criteria, though how many will take advantage of the opportunity to have more than one child remains to be seen.

\section{THE FUTURE OF THE POLICY}

The Chinese government is facing an important challenge: the need to balance the basic human right of reproduction with population growth, which, despite the policy's success, is still increasing at a rate of 8 per 1000, or 10 million people, per year (equivalent to the population of Belgium). In making decisions about the future, several factors must be taken into consideration.

First, relaxation of the policy can be considered only if fertility aspirations are such that a baby boom will not result. There is now good evidence that China is becoming a small-family culture. Data from the National Family Planning and Reproductive Health Survey show that 35 percent of the women questioned preferred having only one child and 57 percent preferred having two children, but very few women (an average of 5.8 percent) wanted more than two $^{29}$ (Table 3). Young, urban, educated women wanted fewer children than did their counterparts in rural areas. In other studies, 75 percent of respondents in wealthy Jiangsu province were sat-

\begin{tabular}{|c|c|c|c|c|c|c|}
\hline Variable & No Children & 1 Child & $\begin{array}{l}2 \text { Children } \\
\text { percent }\end{array}$ & $\begin{array}{l}3 \text { or More } \\
\text { Children }\end{array}$ & No Preference & $\begin{array}{c}\text { Mean No. of } \\
\text { Children Preferred }\end{array}$ \\
\hline \multicolumn{7}{|l|}{ Age (yr) } \\
\hline $15-24$ & 1.9 & 50.0 & 44.0 & 2.1 & 2.3 & 1.5 \\
\hline $25-34$ & 0.8 & 37.0 & 57.0 & 4.5 & 0.7 & 1.7 \\
\hline$\geq 35$ & 0.9 & 27.0 & 63.0 & 9.0 & 0.4 & 1.8 \\
\hline \multicolumn{7}{|l|}{ Place of residence } \\
\hline Rural area & 0.4 & 30.0 & 61.0 & 7.5 & 1.2 & 1.8 \\
\hline Urban area & 3.1 & 52.0 & 43.0 & 1.5 & 0.9 & 1.4 \\
\hline \multicolumn{7}{|l|}{ Educational level } \\
\hline Primary school & 0.4 & 21.0 & 66.0 & 12.0 & 0.9 & 1.9 \\
\hline Middle or high school & 2.1 & 47.0 & 46.0 & 3.9 & 1.6 & 1.5 \\
\hline College & 4.0 & 49.0 & 45.0 & 2.3 & 0.8 & 1.4 \\
\hline Total for all women & 1.1 & 35.0 & 57.0 & 5.8 & 1.1 & 1.7 \\
\hline
\end{tabular}

* Data are from Sun. ${ }^{31}$ 
isfied with their one child regardless of sex, whereas in poorer Yunnan province, 55 percent were satisfied with an only boy, but only 30 percent were satisfied with an only girl. ${ }^{8}$ And in Tibet, where most couples are permitted to have three children, 65 percent of the women wanted only one or two children. ${ }^{32} \mathrm{How}$ ever, the survey also showed that in urban areas of China, where (with very few exceptions) only one child is allowed, 43 percent of women still preferred having two, so the one-child restriction remains unacceptable for nearly half of urban Chinese women.

Second, what was appropriate in 1979 may not be so now. China has undergone massive socioeconomic change during the past 25 years. With the freedoms that have resulted from wealth and globalization, the one-child policy seems increasingly anachronistic. Increased wealth and freedom also make it harder for the government to enforce the policy. Economic disincentives are not a deterrent to many wealthy people, and increased freedom of movement has made it difficult for family-planning authorities to track down people if they choose to flout the regulations.

Finally, the evidence of slowing population growth, the high sex ratio, the increasing number of elderly people, and the risks associated with avoidance of medical care by women with unapproved pregnancies suggest that a relaxation of the onechild policy would be desirable.

Several options for the future have been suggested. One possibility is that everyone could be allowed to have up to two children, with a space of at least five years between them. ${ }^{1}$ It has been predicted that this option would yield a total fertility rate of 1.7 during the next two decades, which would help to normalize the sex ratio, reduce the 4:2:1 phenomenon, and be acceptable to the majority of people.

But the government feels that vigilance is still essential. It is feared that any wavering in implementation of the policy may compromise the goal of keeping the population below 1.4 billion by 2010 , which in turn could threaten economic growth and stability. There are particular concerns about the increasing level of migration from rural to urban areas, which has fueled substantial urban growth.

Therefore, in 2002 it was announced that there would be no fundamental policy changes but that certain aspects of policy implementation would be relaxed. ${ }^{33}$ For example, couples are to be allowed choice in contraceptive methods as part of so-called client-centered family-planning services. These changes have now been introduced in 800 counties (out of a total of 3000), and more are planned. Furthermore, couples no longer need to obtain permission to have a first child, a move that spells the end of the very unpopular system of local birth quotas, which meant that couples were forced to delay pregnancy if the local quota was exceeded. These changes, together with declining fertility aspirations, have reduced (though not eliminated) the tensions associated with the government's efforts to control population growth and have allowed the government to adopt a cautious and gradual approach to relaxing the one-child policy.

From the Center for International Child Health, Institute of Child Health, University College London (T.H.); the Institute of Social and Family Medicine, Zhejiang University, Hangzhou, China (L.L.); and the Institute of Public Health, Zhejiang Normal University, Jinhua, China (Z.W.X.).

1. Greenhalgh $S$, Bongaarts J. Fertility policy in China: future options. Science 1987;235:1167-72.

2. Zhu WX. The one child family policy. Arch Dis Child 2003;88: 463-4.

3. Hesketh T, Zhu WX. The one child family policy: the good, the bad, and the ugly. BMJ 1997;314:1685-7.

4. Yin Q. Choice of contraceptive methods among women of child bearing age and influencing factors. In: Theses collection of 2001 National Family Planning and Reproductive Health Survey. Beijing: China Population Publishing House, 2003:116-26.

5. United Nations Population Fund. Family planning: a human right. (Accessed August 26, 2005, at http://www.unfpa.org/rh/ planning.htm.)

6. Yang Q. Provincial patterns of contraceptive use in China. Asia Pac Popul J 1994;9(4):23-42.

7. Winckler EA. Chinese reproductive policy at the turn of the millennium: dynamic stability. Popul Dev Rev 2002;28:379-418.

8. Hardee K, Xie Z, Gu B. Family planning and women's lives in rural China. Int Fam Plan Perspect 2004;30:68-76.

9. Li J. Gender inequality, family planning, and maternal and child care in a rural Chinese county. Soc Sci Med 2004;59:659-708.

10. Doherty JP, Norton EC, Veney JE. China's one-child policy: the economic choices and consequences faced by pregnant women. Soc Sci Med 2001;52:745-61.

11. Ni H, Rossignol AM. Maternal deaths among women with pregnancies outside of family planning in Sichuan, China. Epidemiology 1995;5:490-4.

12. China Population Information and Research Centre. Basic population data of China: $1949-2000$ and major figures of the 2000 population census. (Accessed August 26, 2005, at http://www.cpirc.org. cn/en/eindex.htm.)

13. Pan JH. Analysis of outcomes of pregnancies and fertility level of married Chinese women. In: Theses collection of 2001 National Family Planning and Reproductive Health Survey. Beijing: China Population Publishing House, 2003:16-26.

14. Short SE, Fengying Z. Looking locally at China's one-child policy. Stud Fam Plann 1998;29:373-87.

15. Merli MG, Raftery AE. Are births underreported in rural China? Manipulation of statistical records in response to China's population policies. Demography 2000;37:109-26.

16. Wang JY. Evaluation of the fertility of Chinese women during 1990-2000. In: Theses collection of 2001 National Family Planning and Reproductive Health Survey. Beijing: China Population Publishing House, 2003:1-15. 
17. United Nations Development Programme. Total fertility rates: 2003. (Accessed August 26, 2005, at http://www.undp.org/hdr2003 indicators/indic_47_1_1.html.)

18. Davis DL, Gottlieb MB, Stampnitzky JR. Reduced ratio of male to female births in several industrial countries: a sentinel health indicator. JAMA 1998;279:1018-23.

19. Kang C, Wang Y. Sex ratio at birth. In: Theses Collection of 2001 National Family Planning and Reproductive Health Survey. Beijing China Population Publishing House, 2003:88-98.

20. Coale AJ, Banister J. Five decades of missing females in China. Demography 1994;31:459-79.

21. Lofstedt P, Shusheng L, Johansson A. Abortion patterns and reported sex ratios at birth in rural Yunnan, China. Reprod Health Matters 2004;12:86-95.

22. Bogg L. Family planning in China: out of control? Am J Public Health 1998;88:649-51.

23. Wu ZC, Viisainen K, Wang Y, Hemminki E. Perinatal mortality in rural China: retrospective cohort study. BMJ 2003;327:1319.

24. Tuljapurkar S, Li N, Feldman MW. High sex ratios in China's future. Science 1995;267:874-6.

25. Tucker JD, Henderson GE, Wang TF, et al. Surplus men, sex work, and the spread of HIV in China. AIDS 2005;19:539-47.

26. Hudson VM, den Boer AM. A surplus of men, a deficit of peace: security and sex ratios in Asia's largest states. Int Secur 2002;26(4): 5-38.

27. Gu B, Roy K. Sex ratio at birth in China, with reference to other areas in East Asia: what we know. Asia Pac Popul J 1995;10: $17-42$

28. World Bank Health Nutrition and Population Division. Development data. (Accessed August 26, 2005, at http://www.worldbank. org/hnpstats.)

29. Lin B. Fertility desires of women of childbearing age and influencing factors. In: Theses collection of 2001 National Family Planning and Reproductive Health Survey. Beijing: China Population Publishing House, 2003:57-65.

30. Peng P. Causes and consequences of fertility decline in China. China Popul Today 1998;15(3):5-6, 10.

31. Sun F. Ageing of the population in China: trends and implications. Asia Pac Popul J 1998;13(4):75-92.

32. Chen H. Fertility desires of married Tibetan women of childbearing age in Tibet. China Popul Today 1997;14(3-4):24.

33. No relaxation of Chinese one couple, one child policy. People's Daily Beijing. September 2, 2002. (Accessed August 26, 2005, at http: //english.peopledaily.com.cn/200209/01/eng20020901_102440. shtml.)

Copyright (c) 2005 Massachusetts Medical Society.

FULL TEXT OF ALL JOURNAL ARTICLES ON THE WORLD WIDE WEB

Access to the complete text of the Journal on the Internet is free to all subscribers. To use this Web site, subscribers should go to the Journal's home page (www.nejm.org) and register by entering their names and subscriber numbers as they appear on their mailing labels. After this one-time registration, subscribers can use their passwords to log on for electronic access to the entire Journal from any computer that is connected to the Internet. Features include a library of all issues since January 1993 and abstracts since January 1975, a full-text search capacity, and a personal archive for saving articles and search results of interest. All articles can be printed in a format that is virtually identical to that of the typeset pages. Beginning six months after publication, the full text of all Original Articles and Special Articles is available free to nonsubscribers who have completed a brief registration. 